\title{
Como se (des)faz um armário português
}

\section{Fernando Curopos}

\section{Sorbonne Université}

Resumo: A partir de uma leitura diacrónica da recepção do Só, de António Nobre, tentaremos demonstrar como a crítica praticou um verdadeiro "closeting", tanto da obra quanto do autor. Embora esse branqueamento se possa entender tendo em conta os tabus ligados à sexualidade durante o Estado Novo, o armário continuará muito tempo depois, inclusive por parte de um dos maiores críticos do poeta, o escritor Mário Cláudio, ele próprio homossexual no armário, como virá a admitir em Astronomia (2015).

Palavras-chave: António Nobre, Mário Cláudio, homofobia, armário, homossexualidade e literatura

\begin{abstract}
From a diachronic reading of the reception of Só, by António Nobre, we will try to demonstrate how Portuguese critics have closeted the poet and his production. This closeting can be understood in the light of the sexual taboos prevailing during the Estado Novo. Nonetheless, this closeting will continue long afterwards, including by one of the poet's greatest critics, the writer Mario Cláudio, himself a homosexual in the closet, as he will admit in Astronomy (2015).
\end{abstract}

Keywords: António Nobre, Mário Cláudio, homophobia, closet, homosexuality and literature 
No rescaldo da crise provocada pelo ultimato inglês de 1890 e num país que Antero de Quental considera como "um país eunuco" (Quental 1895: 114), os críticos anseiam por livros "viris" capazes de regenerar a Pátria, como Trindade Coelho e Alfredo da Cunha deixam claro no primeiro número da Revista Nova, de 1893:

Na crise aguda que atravessamos - crise complexa de moralidade e de intelectualidade, de pobreza económica e de miséria mental - urge, para que nos não anulemos numa passividade que tocaria as raias da idiotia, que cada um, na sua esfera de trabalho e de apostolado, se eleve à compreensão duma necessidade, primeira entre todas: - a de reagir virilmente contra a onda triunfante de estrangeirismo, que tudo vai deixando submerso em vasa e lodo, e de, ao mesmo tempo, numa regressão ao passado, ir buscar alento e estímulo para a iminente revolução do futuro. (Pereira 1995: 54-55)

O Só, que António Nobre publica em Paris em 1892, pertence a essa "onda de estrangeirismo", sendo um livro que a crítica coeva considera de imediato como pouco viril:

Nasceram velhos, a sua primeira infância é a segunda! Na idade em que os Romanos tomavam a toga viril, põem eles bibes! Tem a gente vontade de lhes dizer: "Os meninos querem fazer ó... ó". O Sr. António Nobre, quando fala de si, diz sempre “0 António!” Coitadinho do bébé. (Chagas 1892: 1)

Pinheiro Chagas será assim um dos primeiros a denunciar o "carácter brando e sem virilidade" (Bessa-Luís 1995: 10) do Só. Sem "virilidade" porque o sujeito poético se apresenta como um ser cujas aspirações e qualidades não coincidem com a imagem associada ao homem e à masculinidade. Mostra-se pelo contrário atraído por estados letárgicos, pela passividade, pela tristeza e as lágrimas (Curopos 2009a: 97-121). Daí Trindade Coelho atacar um livro "onde o poeta como que nos surge [...] dando-nos da sua alma alanceada a visão confrangedora de um farrapo, em lágrimas ensopado" (Coelho 1892: 117). Numa época em que o Parnasianismo ostenta a impassibilidade como poética e o Simbolismo à maneira de Verlaine refreia a expressão dos sentimentos, Nobre expõe os seus, até ao excesso, até às lágrimas. Embora as lágrimas não sejam o apanágio das mulheres, foram nos finais do século XIX, por rejeição do ultrarromantismo, consideradas 
como modo de expressão feminina e, nos homens, como marca de efeminação (VincentBuffault 1986).

O Só é portanto mal recebido pelos contemporâneos do autor, pouco atentos à sua modernidade e avessos à "sua graça espiritual e feminina", segundo a expressão de Teixeira de Pascoaes (1911: 2), o qual considera Nobre como "a nossa maior poetisa" (Andrade 2011: 34). José Régio chega mesmo a concluir, em 1925, que “a Arte de António Nobre pode ser tida por feminina" (Régio 1944: 191-192). Em 1967 é o próprio poeta que Régio considera como feminino: "certamente se poderá falar da feminilidade [...] de António Nobre". Seguindo essa vertente crítica, a brasileira Nelly Novaes Coelho define o autor como "feminóide", "emotivo, tímido e pouco viril" (Coelho 1964: 67, 72), opinião partilhada por Isabel Cardigos: "quão rica e ousada é a feminilidade desse homem, António Nobre" (Cardigos 1991: 25). Logo, a feminilidade do poeta parece ser, para muitos críticos, quer homens, quer mulheres, uma evidência intuitiva, um dado da simples leitura. Na opinião de Vergílio Ferreira, a sua escrita revela "um feminismo equívoco. [...] Ora tal feminilidade, [...] irrita-nos bastante." (Ferreira 1990: 239). Aliás, Ferreira fica quer irritado quer divertido com a pretensa feminilidade do poeta: "Faz-nos sorrir o seu dandismo provocatório. Porque a provocação fala do lutador e o dandismo da sua feminilidade" (Ferreira 1993: 17).

Esse irritante "feminismo equívoco", prolongamento da falta de virilidade sublinhada logo à partida pelos críticos coevos, não passa de uma enunciação do "interdito", um armário construído pela crítica e no qual permaneceu trancado António Nobre. De facto, embora Jorge de Sena tenha sido o primeiro, ainda em 1969, a entreabrir o armário nobreano e a associar a palavra homossexualidade à sua escrita, essa linha de leitura pouco interessou aos estudiosos do autor:

O infantilismo de Nobre, a sua homossexualidade que se desconhece, o seu desejo de uma mulher que seja purinha, o seu efeminamento de homem à femmes sem mulheres, [...] o seu narcisismo adolescente, são, ao nível do génio e da grande poesia, o mais completo e mais sinistro retrato do solipsismo lusitano [...] que se compraz masoquisticamente na ideia da morte, para fugir ao sadismo essencial à agressividade sexual, ou escapar à naturalidade de aceitar o sexo em si mesmo. (Sena 1992: 59) 
O natural da sexualidade parece estar ausente dos versos do poeta, consequência, na opinião de Joaquim Manuel Magalhães, num artigo publicado em 2006, "da dimensão enclausurada de uma mente e de um corpo sujeito a várias necessidades de (des)representar-se perante a normatividade do mundo português do seu tempo, em grande parte ainda hoje continuado" (Magalhães 2006: 68-69). Ora, como nota Jorge de Sena:

[...] sucede que, no amor e no sexo, como em tudo, se requer, menos do que tempo, espaço, no sentido de dimensão psico-social da liberdade erótica - e isso é incompatível com as quatro paredes da incestuosa aldeia mental que os portugueses transportam consigo pelo mundo, ou erguem à sua volta no país, e em que a liberdade do sexo [...] se reduz a uma espécie de conivência clandestina. (Sena 1992: 67)

Esse comentário a propósito do Só, escrito nos Estados-Unidos em plena revolução sexual, parece-nos apropriada para falar das "quatro paredes" que permaneceram de pé após o 25 de Abril, como notado por Joaquim Manuel Magalhães. Exemplo disso será José Seabra Pereira, outro estudioso de António Nobre, que só tocará de leve em tão melindroso assunto num livro dedicado ao poeta e publicado em 2001: "a figura de Purinha e o cognato ideal amoroso ressentem-se do ambíguo erotismo e do androginismo que obsidiam e complicam a semântica dos afetos e do desejo na poesia de António Nobre" (Pereira 2001: 47). É de notar os rodeios do crítico - "ambíguo erotismo", "androginismo" - para não dizer francamente "o amor que não ousa dizer o seu nome". Quanto ao crítico Fernando Pinto do Amaral, fala em pulsões homossexuais no autor, pondo logo um ponto final nessa veia interpretativa: "o sofrimento sempre foi o único amante deste poeta algumas vezes ligado a pulsões homossexuais que não importa debater" (Amaral 1993: 83).

Se para esse crítico, e para muitos outros, este assunto não merece ser debatido, parece-nos evidente que é da maior importância para o estudo do próprio Nobre, enclausurado no seu armário íntimo. Assim sendo, os estudiosos do poeta adotam a posição do dominante, tal como a definiu o sociólogo Didier Éribon: 
É sempre fácil para os que ocupam, no âmbito de uma interação, a posição dominante, não ver ou não querer ver os efeitos da dominação, e como os outros foram, no corpo e no espírito, constituídos por uma lenta e irresistível impregnação dos seus efeitos maciços e invisíveis. É mesmo importante para esses dominantes negá-los, ou subestimá-los: caso não, isso os obrigaria a perguntarem-se sobre a sua participação, no decorrer do dia-a-dia, nessa dominação e na perpetuação da mesma. (Éribon 2013: 178-179)

A crítica portuguesa empenhou-se, até hoje, em fugir ao assunto, perpetuando deste modo uma violência simbólica contra o autor. Com efeito, Nobre não "se compraz masoquisticamente na ideia da morte" (Sena 1992: 59), nem "o sofrimento [...] foi o [seu] único amante" (Amaral 1993: 83). Pois, a pulsão de morte premente no poeta é, como notou Joaquim Manuel Magalhães, a mera consequência da "sufocação de um país que não o deixa existir plenamente. [...] Ele sabe que o seu país lhe dá morte, simplesmente" (Magalhães 2006: 69).

O Só é tido logo à partida como um ato de revolta contra as normas de género e a heteronormatividade, o que, no Portugal finissecular, constitui um ato de pura heresia que pode levar a uma quase morte social. Daí a opinião de Agustina Bessa-Luís, para quem “o Só é a história duma separação abissal, e a sociedade toma-o assim: como um segredo inatural que fica descoberto. Heresia da lei estabelecida" (Bessa-Luís 1995: 10). Portanto, o segredo que a escrita revela seria de ordem "inatural", uma homossexualidade que, no Portugal da época, o Estado, a elite republicana e o discurso médico e jurídico começam a combater de maneira sistemática. Com efeito, embora os historiadores deem como ponto de partida o julgamento de Oscar Wilde como elemento crucial de uma maior difusão e mediatização das questões relativas à homossexualidade na Europa, em Portugal, é um homem político, D. José de Menezes e Távora Rappach da Silveira e Castro, Marquês de Valada (1826-1895), que virá dar corpo e cara à figura do homossexual recém-inventada pela medicina psiquiátrica. Na noite de 2 de agosto de 1881, o nobre foi "surpreendido pela polícia na Travessa da Espera, n. $.^{\circ} 63,1^{\circ}$, em repreensíveis libidinosidades com um soldado" (Monteiro 1922: 188). Ora o marquês era, na altura, "governador civil substituto de Lisboa, 
uma das vozes mais conservadoras do Partido Regenerador na câmara alta e amigo pessoal do rei" (Carvalho 2010: 150).

Os jornais republicanos apoderam-se do caso para abalar o governo e a monarquia, inscrevendo o marquês "numa tradição secular, a do conselheiro exercendo a sua má influência, o seu poder corruptor no corpo do Estado, no sentido literal e figurado" (Murat 2006: 264): "o caso era tanto mais grave e escandaloso porque o marquês de Valada era um importante par do reino, o que demonstrava a 'valia moral' da câmara que acabou por ditar o fim do governo progressista" (Carvalho 2010: 150). Até à sua morte, o marquês será alvo de ataques ad hominem e associado, nas caricaturas que lhe dizem respeito, a outro representante do poder político, o Ministro dos Negócios Estrangeiros do governo de Ernesto Hintze Ribeiro, Carlos Lobo d'Ávila (1860-1895), “o inverso sr. Carlos de Valbom” (s.n. 1895: 1), mais conhecido por Carlota no meio republicano (Curopos 2016a: 40). Só a morte precoce do Ministro em 1895 impedirá que os jornais da época façam dele um novo Marquês de Valada. Convém notar que a bandeira política não imuniza contra a homofobia. Pois, o jornalista republicano Heliodoro Salgado (1861-1906), ainda do tempo do Marquês de Valada, também será vítima de um “outing” por parte do mais acirrado caricaturista da época, Manuel Bordalo Pinheiro.

A homofobia torna-se, portanto, uma arma de combate político e a homossexualidade é associada, pelos republicanos, a uma nobreza degenerada (Curopos 2018: 135-149). Por conseguinte, não é de estranhar o sucesso de O Barão de Lavos, primeiro romance português a falar abertamente de homossexualidade masculina (Curopos 2016a: 58-74), publicado em 1891 por um republicano convicto, Abel Botelho (1856-1917), um dos primeiros detratores do Só.

Todavia, embora a encenação de sexualidades não normativas na ficção, na poesia satírica e no teatro de revista da época ou a denúncia de casos nos jornais tivesse uma função ideológica, a de associar a “degenerescência moral e sexual” com a própria degenerescência de um regime moribundo e anacrónico (a monarquia), é de notar que o governo da época já tinha posto em prática a "limpeza" tão ansiada pelo jornal republicano A Vanguarda: 
Demasiada até se tornar criminosa tem sido a condescendência havida até hoje para um sem número de abjetos, de pervertidos, que, sendo homens, não merecem esse nome.

Que a condescendência se transforme em severidade, se isso não é impossível, se os que têm o dever de ordená-la podem efetivamente fazê-lo.

É o que a imprensa deve exigir, ao ocupar-se desta escandalosíssima podridão. (A Vanguarda 1895: 2)

Com efeito, a partir de 1881, o Governador Civil de Lisboa, António Maria Barreiros Arrobas (1824-1888), lança uma campanha de saneamento contra a prostituição na capital. Embora as rusgas tenham como alvo a prostituição feminina de rua, a "caça às borboletas movida pela Polícia Sanitária" (Pais 1983: 950), abrangem também a prostituição masculina, rusgas incentivadas por Bordalo Pinheiro e os jornalistas da revista $O$ António Maria: "sabermos quem são as Lolas que se vendem é bom; não ignorarmos quem são os Afonsos que se compram é ótimo" (O António Maria 1881: 194). Assim, desde 1881, os espaços de sociabilidade, de prostituição masculina ou de cruising homossexual, como a praça do Rossio, o Terreiro do Paço, o Alto da Avenida ou o Jardim do Príncipe Real, estão sob apertada vigilância da polícia:

Já em 1883, foram presos n[o] Príncipe Real pelas dez horas da noite cinco indivíduos [...] verdadeiros prostitutos públicos. As autoridades conseguiram a sua detenção da seguinte forma: alguns agentes fingiram-se passar por descuidados passeantes, sentaram-se nos bancos e esperaram, e pouco depois os tais indivíduos chegando-se e entabulando conversas, mal sabendo que falavam com a polícia. (Aguiar 1926: 553)

É, portanto, numa época de repressão à homossexualidade e, por conseguinte, da sua exposição pública, que António Nobre publica Só, parodiado de imediato por Eugénio Sanches da Gama, aliás Estephánio Rimbó, no seu Nós Todos (1892). Dos onze poemas do livro, seis são paródias de composições do livro de Nobre, "Bachanal soturna", "Os Sabbados", “Natal do Rimbó", “Ai de mim!", “Pores de lua” e "Carta ao Miguel”, o que levará Nobre a alterar ou suprimir alguns poemas aquando da publicação da segunda edição, em 1898. Numa das paródias de Sanches, Nobre aparece associado ao seu muito amigo Alberto de Oliveira: 
Dedo mindinho

É o Albertinho.-

- António Nobre

O seu vizinho

(Sanches 1892: 8)

Ora o gay-bashing da imprensa republicana contra algumas figuras públicas e as rusgas policiais provocam um verdadeiro pânico nos sujeitos homossexuais ou naqueles que podiam ser tidos como tais, como os muito amigos Alberto de Oliveira e António Nobre. A sua relação com o poeta neogarrettista está rodeada de uma misteriosa ambiguidade que o levará a uma brusca rutura em 1893 e à destruição da sua correspondência. Só algumas cartas escritas ao seu "Purinho" "Santo Alberto" escapariam ao holocausto:

Há, contudo, nos usos sociais certas fórmulas de cortesia que em algumas circunstâncias se aplicam, tal a correspondência que se troca entre homem e menina. Ora o Sr. Alberto de Oliveira foi a menina da nossa correspondência. Confiado na dignidade de cada qual, enceta-se uma palestra postal que, às vezes [...] acaba, um dia, e, nesse dia, se troca. Que seria ao contrário da reputação dos amorosos correspondentes? O nosso "Diário" está nesses casos. Seria a minha morte moral o seu conhecimento. (Nobre 1982: 186)

Todavia, parece que essa amizade se terá limitado, segundo a opinião de Guilherme de Castilho, biógrafo do autor, a uma "amizade amorosa" (Castilho 1980: 147), quase exclusivamente epistolar, portanto longe do corpo. Porém, as poucas cartas salvas demonstram toda a complexidade dos afetos que unem o autor ao seu amigo Alberto, com quem travou conhecimento na universidade de Coimbra:

Ah! sinto agora bem quanto é grande a minha Amizade por ti, maior do que Amor, quase Adoração. [...] Tu passaste a ser hoje santo da minha devoção. [...] Olha, ainda há bocadinho, ao cabo do jantar, quando o criado ao servir-me chá me perguntou: "Milk also?" eu respondi “No", mas logo reflectindo, pensando em ti, tomei "Milk, yes!" Bebi leite e por isso me sinto tão bem: é que a tua Alma anda a ungir-me toda diluída, as minhas entranhas. (Nobre 1982: 109) 
A evocação dessa amizade traduz-se na correspondência por uma associação Alberto/leite, "os olhinhos-leite de Santo Alberto" (Nobre 1982: 141), um leite que dá prazer e penetra até as "entranhas": "Mas quero que sejas sempre muito bom e me digas sempre os teus versos com leite a escorrer de toda a parte: - olhos, boca, coração" (Nobre 1982: 153). Logo, a relação é de cariz amorosa com uma componente sexual inibida; a única referência explícita ao sexo faz-se através de uma referência pueril que revela uma sexualidade ainda por acontecer: "Também te quero dizer que o Britannia nasceu em 1873, tendo pois a tua idade. [...] há esta coincidência, mas eu não consinto que a tua pilinhamorango toque nem de leve o vergalho deste paquete" (Nobre 1982: 116).

Contudo, qualquer que fosse a relação entre Nobre e Alberto de Oliveira, a sua rutura terá uma repercussão na arquitetura do Só; o soneto "Ó Condezinho de Tolstoï (Alberto)" dedicado ao seu amigo e publicado na primeira edição do livro desaparece aquando da sua reedição. Essa rasura parece significar textualmente e quase publicamente o fim da "ligação" entre os dois "amorosos amigos":

Ó condezinho de Tolstoï (Alberto)

Santo da minha extrema devoção,

Alma tamanha, que adorei de perto,

Lá na Thebaida de Sr. João.

Meu Calix do Senhor! Meu Pallio aberto!

Luar branco na minha escuridão!

Ó minha Joanna d'Arc! Amigo certo

Na hora incerta! Aguia! meu irmão!

A ti as Terças-feiras, n'este Inferno,

D'aquelle que nasceu, em terça-feira

E em terça-feira morrerá, talvez...

Quando eu for morto já, noites de inverno,

Aos teus filhinhos, conta-as á lareira

Para eu ouvir de lá :

“Era uma vez..." (Nobre 1892: 38) 
É de notar que Nobre chamava ao seu amigo "Santo", "Purinho" ou "Betinho" (Nobre 1988: 77; 95) na sua correspondência, nomes que o associam, no imaginário do poeta, à "Purinha" do Só. "Purinha" é um amor idealizado socialmente admitido. "Purinho"/Alberto seria a sua vertente inconsciente, um amor platónico (?) marginalizado por uma sociedade que condena qualquer agressão à heteronormatividade, o que levará Agustina Bessa-Luís a definir o Só como um "acto de repressão dum reprimido" (Bessa-Luís 1995: 10).

No entanto, embora a crise de género e a rutura com a heteronormatividade patente nos versos do poeta sejam um dado essencial para entender o livro de "um homem Só" (Curopos 2009b), o fato é que a crítica portuguesa procurou sempre apagá-las, um "branqueamento" (Cascais 2004: 14) também válido para muitos outros autores, como já notou António Fernando Cascais, retrato da continuada homofobia no Portugal do pós-25 de Abril (Curopos 2016b: 11-14).

Tal apagamento acontece também na crítica de um dos maiores estudiosos e divulgadores do poeta, o escritor portuense Mário Cláudio (1941-), editor da obra completa de António Nobre, de quem também editou o caderno de apontamentos. No entanto, tanto no aparato crítico quanto nos onze artigos sobre a obra do poeta, Claúdio nunca falará abertamente "do amor que não ousa dizer o seu nome":

Como quer que fosse, a aventura parisiense dos dois amorosos amigos, sintomática de uma certa partilha de coitos clandestinos, de que se fabricam as difusas relações de adolescentes inumeráveis, não deixará de nos convidar a refletir, com toda a digna e necessária ternura, que a moralidade nos impõe. (Cláudio 2004: 51)

Em 1993, data da redação e publicação desse artigo na conceituada revista portuguesa Colóquio/Letras, o crítico convida-nos a refletir, mas sempre dentro dos limites impostos pela moral heterossexual que ele próprio reproduz e de que não se consegue libertar. Com o tempo, essa moral torna-se menos rígida e o escritor/crítico acompanha a mudança da própria sociedade portuguesa. Ao falar, numa entrevista, do seu conto "António Nobre e Alberto de Oliveira", Cláudio indica: 
Essa história é uma história que só hoje é que se pode contar porque, entretanto, os tempos mudaram. Embora não seja uma história de amores homossexuais, porque eu admito que nunca tenha havido uma concretização da relação do António Nobre com Alberto de Oliveira, é uma história com uma carga homoerótica muito grande e o homoerotismo é alguma coisa em que, até relativamente pouco tempo, ninguém tinha o direito de tocar. (apud Gomes 2009: 47)

Entre a redação do primeiro artigo e a publicação do conto, a sociedade portuguesa mudou muito, libertando a palavra perante um tabu social: a homossexualidade. Logo, a "amizade" entre os dois amigos torna-se mais clara: "é uma história com uma carga homoerótica muito grande". Se o crítico e escritor Mário Cláudio encara a relação entre os dois amigos sob o prisma de uma homossexualidade sublimada, é que Nobre constitui, para o próprio Cláudio, uma espécie de espelho do seu próprio armário:

A nossa aventura foi vivida em Inglaterra, onde havia tabus e tradições vitorianas, mas a abertura era muito maior. Em Portugal teria sido inimaginável. Ainda há pouco tempo comentei com esse meu amigo que se os tempos em que nos conhecemos fossem os de agora, quem sabe se não poderíamos ter constituído família. Mas hoje sinto-me absolutamente incapaz de casar com um homem. Não é algo que condene, pelo contrário, mas não me vejo nessa situação, ainda tenho dentro de mim o repressor antigo. (Queirós 2015: s.p.)

Portanto, só em 2015 é que o autor sairá, ao publicar a sua autobiografia, do seu armário interiorizado (Cláudio 2015: 233-245), indicando numa entrevista: “Uma das grandes vantagens da idade é perder-se a vergonha: deixa-se de ter preocupações sobre o que os outros vão pensar disto ou daquilo, do que somos ou não somos, das nossas opções de vida." (Queirós 2015: s.p.). Tanto a autobiografia de Cláudio, quanto os seus artigos sobre o poeta António Nobre, mostram os efeitos da dominação e o "assujeitamento", a continuada repressão ou autorrepressão às temáticas e modos de vida queer após o 25 de Abril. Afinal, e contrariamente à hagiografia da Revolução, a liberdade não foi para todos nem para todas. 


\section{Bibliografia}

Aguiar, António Asdrúbal d' (1926), "Evolução da pederastia e do lesbismo na Europa: contribuição para o estudo da inversão sexual", in Arquivo da Universidade de Lisboa, vol. XI, 335-620.

Andrade, Eugénio de (2011), Prosa, Vila Nova de Gaia, Modo de Ler.

Amaral, Fernando Pinto do (1993), "A Poesia como doença da alma - Uma abordagem do Spleen no Só", in Colóquio/Letras, n. ${ }^{\circ}$ 127-128, 77-86.

Bessa-Luís, Agustina (1995), “Introdução ao Só”, in Só, Porto, Livraria Civilização Editora, 7-14.

Cardigos, Isabel (1995), “Os Figos Pretos de António Nobre”, in Colóquio/Letras, n. 120, 25-40.

Carvalho, Mariano Cirilo de (2010), O Poder Oculto do Liberalismo Progressista (1876-1892), Alfragide, Texto Editores.

Cascais, António Fernando (org.) (2004), Indisciplinar a Teoria: Estudos Gays, Lésbicos e Queer, Lisboa, Fenda.

Castilho, Guilherme de (1980), Vida e Obra de António Nobre, Lisboa, Bertrand.

Chagas, Pinheiro (1892), "Só", in Correio da Manhã, Lisboa, 13 de agosto, 1.

Cláudio, Mário (2004), "Rua dos dois amigos, outras pedras", in Pagínas nobrianas (2004), Porto, Edições Caixotim, 47-52.

-- (2015), Astronomia, Lisboa, D. Quixote.

Coelho, Nelly Novaes (1964), "O Tempo e a morte: duas constantes da poesia de Antônio Nobre", in Tempo, solidão e morte, São Paulo, Conselho Estadual de Cultura, 41-76.

Coelho, Trindade (1892), “Os Poetas novos", in Revista Ilustrada, 3. ${ }^{\circ}$ ano, n. ${ }^{\circ} 48,1892$. Apud Guimarães, Fernando (1990), Poética do Simbolismo em Portugal, Lisboa, Imprensa Nacional - Casa da Moeda, 113-119.

Coelho, Trindade / Cunha, Alfredo da (1893), "Apresentação", Revista Nova, n. ${ }^{\circ}$, in Pereira, José 
Carlos Seabra (1995), História crítica da literatura portuguesa, vol. VII, Lisboa, Verbo, 54-55.

Curopos, Fernando (2009a), António Nobre et la Crise du Genre, Paris, L’Harmattan.

-- (2009b), “Um homem Só”, in Telhados de Vidro, n. 12, 107-120.

-- (2016a), L'Émergence de l'homosexualité dans la littérature portugaise (1875-1915), Paris, L'Harmattan.

-- (2016b), Queer(s) Périphérique(s) : Représentation de l'Homosexualité au Portugal (19742014), Paris, L'Harmattan.

-- (2018), "Contra os queers, marchar, marchar!", in Via Atlântica, São Paulo, n. ${ }^{\circ} 33$, Jun/2018, 107-120.

Éribon, Didier (2013), La Société Comme Verdict, Paris, Fayard.

Ferreira, Vergílio (1990), “Breve nota sobre o Só”, in Espaço do invisível - I, Lisboa, Bertrand, 239-246.

-- (1993), "Serás poeta e desgraçado", in Colóquio/Letras, n. 127-128, 17-26.

Gama, Eugénio Sanches da (Estephanio Rimbó) (1892), Nós Todos, Coimbra, Imprensa Independência.

Gomes, Graça Joana da Cruz (2009), História, fiç̧ão e trangressões em "Triunfo do Amor Português" de Mário Cláudio, Dissertação de Mestrado em Literatura Portuguesa Investigação e Ensino (História e Periodização da Literatura Portuguesa II), Faculdade de Letras da Universidade de Coimbra.

“Lisboa Devassa” (1895), A Vanguarda, 14 de fevereiro, 2.

Magalhães, Joaquim Manuel (2006), "António Nobre em plena luz", in Revista Actual, Expresso, 1. de abril, 68-69.

-- (2010), Um Toldo vermelho, Lisboa, Relógio d'Água.

Monteiro, Arlindo Camilo (1922), Amor Sáfico e Socrático. Estudo Médico-Forense, Lisboa, Instituto de Medicina Legal.

Murat, Laure (2006), La Loi du genre, Paris, Fayard. 
Nobre, António, Só (1892), Paris, Léon Vanier Éditeur.

-- (1988), Correspondência, Organização, introdução e notas de Guilherme de Castilho, Lisboa, Imprensa Nacional Casa da Moeda.

-- (1995), Só, Porto, Livraria Civilização Editora.

O António Maria (1881), 23 de junho, 194.

Pascoaes, Teixeira de (1911), “António Nobre”, in A Águia, 1. érie, n. 10, julho, 2.

Quental, Antero de (1895), “Nota ao poemeto 'Na Agonia da Pátria”, in Alberto Osório de Castro, Exiladas, Coimbra, Francisco Amado Editor, 114.

Régio, José (1944), “António Nobre”, in António Nobre, Despedidas, Imprensa Moderna, Porto, 191-192.

-- (1967), “António Nobre”, in O Tripeiro, Série VI, Ano VII, 8, 230-232.

Pais, José Machado (1983), "A prostituição na Lisboa boémia dos inícios do século XX", in Análise Social, vol. XIX (77-78-79), 3. ㄴ, 4., 5., 939-960.

Pereira, José Carlos Seabra (1995), História Crítica da Literatura Portuguesa, Lisboa, Verbo Editora, 54-55.

-- (2001), O essencial sobre António Nobre, Imprensa Nacional Casa da Moeda, Lisboa.

Queirós, Luís Miguel (2015), "Entrevista a Mário Cláudio", in Público, 16 de setembro. $<$ http://www.publico.pt/culturaipsilon/noticia/quando-se-chega-aqui-ou-se-diz-tudo-oumais-vale-ficar-calado-1711112> (último acesso em 15/05/2018).

“República e Monarquia” (1895), Defensor do Povo, Coimbra, 21 de junho, 1. Sena, Jorge de (1992), Amor e outros verbetes, Edições 70, Lisboa.

Vincent-Buffault, Anne (1986), Histoire des Larmes, Paris, Éditions Rivages. 
Fernando Curopos é Professor Associado com Agregação na Sorbonne Université. É professor de literatura portuguesa, de civilização brasileira e de tradução. Trabalha sobre género, sexualidade, relações interartes e temáticas queer na literatura portuguesa (sécs. XIX-XXI) e no cinema português. É autor de António Nobre ou la crise du genre (2009), prefácio de Joaquim Manuel Magalhães, Paris, L'Harmattan; L'Émergence de l'homosexualité dans la littérature portugaise (1875-1915) (2016), Paris, L'Harmattan; Queer(s) périphérique(s): représentation de l'homosexualité au Portugal (1974-2014) (2016), Paris, L'Harmattan. Coordenou, com Maria Araújo da Silva, Paris, Mário de Sá-Carneiro et les autres (2017), Paris, Éditions Hispaniques. 